\section{Protection and restoration are needed to reverse damage caused by mobile fishing gear}

Surveys of an area once home to numerous horse mussel beds showed that damage from mobile fishing gear depleted the abundance of the species from well over 100 mussels per square meter to just four mussels per square meter in 2010. After banning all mobile fishing gear for seven years, the ecosystem had not recovered. Horse mussels act as a keystone species, so without a critical number of mussels in the habitat, other species are unable to come back. Restoration efforts are needed alongside spatial protection to fix the damage caused.

Mobile fishing gear, especially heavier gear like hydraulic dredges for harvesting razor clams, can cause great damage to seafloor habitats. Soft species, like sponges and soft corals, are especially vulnerable. These species are also slow-growing, so natural recovery can take a long time.

The UK's Strangford Lough was an important horse mussel fishery. Beds of horse mussels are important providers of ecosystem services and are considered a habitat of great conservation importance in the EU. The Lough used to have massive horse mussel beds, but in the 1980s, surveys showed that damaged caused by mobile fishing gear had destroyed much of the habitat: 54\% was lost between 1986 and 2007. As a result, the area was declared Northern Ireland's first Marine Nature Reserve, among other spatial protections. In 2003, a total ban on mobile fishing gear was introduced to halt further damage. The authors of this study surveyed the seafloor in both the north and south basins of the Strangford Lough at the time of the total ban in 2003 and again in 2010 to determine how the ecosystem was recovering.

Statistically significant declines in in horse mussel populations were found between 2003 and 2010 in both basins of the Lough. Average density in the north basin was reduced by $83 \%$, with the south basin declining at $80 \%$. Sponge, cnidarian, bryozoan, and tunicate species declined by $64 \%$ in the north basin. Molluscs reduced in number by $40 \%$. The overall abundance of macroinvertebrates in both basins, however, increased. The abundance of starfish, sea urchins, crab, and shrimp reamined about the same.

Statistical analyses showed that horse mussels function as a keystone species. With the massive losses in horse mussel beds, other species that depend on them cannot survive. Once a critical number of horse mussels were lost, these dependent species declined quickly. Queen scallops disappeared from these areas entirely, showing that horse mussels are important for other commercially-harvested species to grow. To illustrate just how many horse mussels were lost: historical records documented well over 100 mussels per square meter, but only four mussels per square meter were found in 2010.

It is clear from these results that banning mobile fishing gear and waiting several years is not enough to fix a damaged ecosystem. Restoration efforts are needed alongside spatial protection plans.
This is a summary of: Protection alone may not promote natural recovery of biogenic habitats of high biodiversity damaged by mobile fishing gears

Accessible at: https://marxiv.org/ewbdv

Authors: Jose FariñasFranco, Louise Allcock, Dai Roberts

\section{Added to MarXiv:}

May 2018

Published: Marine Environmental Research, 2018

Suggested Citation: Protection and restoration are needed to reverse damage caused by mobile fishing gear. OCTO (2018). DOI: 10.17605/OSF. IO/2XRGP

See more MarXiv summaries at https://www.marxivinfo.org/ summaries

Join the MarXiv Summaries monthly newsletter at https:// oct.to/marxivsum

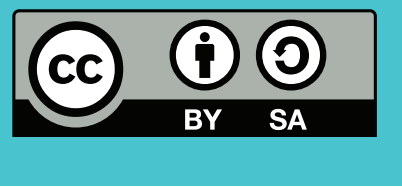

MarXiv is an ОстO Initiative

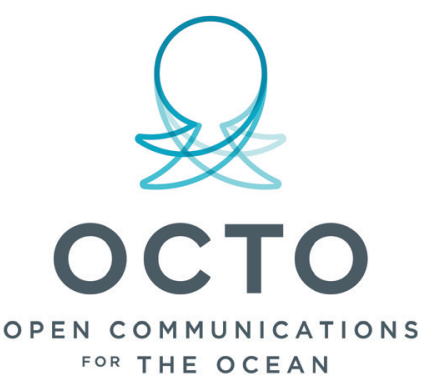

